\title{
Grânulos de amido e fitólitos em cálculos dentários humanos: contribuição ao estudo do modo de vida e subsistência de grupos sambaquianos do litoral sul do Brasil
}

\author{
Verônica Wesolowski* \\ Sheila MariaFerraz Mendonça de Souza* \\ Karl Reinhard** \\ Gregório Ceccantini***
}

\begin{abstract}
WESOLOWSKI, V.; MENDONÇA DE SOUZA, S.M.F.; KARL REINHARD, K.; CECCANTINI, G. Grânulos de amido e fitólitos em cálculos dentários humanos: contribuição ao estudo do modo de vida e subsistência de grupos sambaquianos do litoral sul do Brasil. Revista do Museu de Arqueologia e Etnologia, São Paulo, 17: 191-210, 2007.
\end{abstract}

Resumo: Este artigo tem por objetivo apresentar os resultados da recuperação e análise de micro-vestígios vegetais retidos em cálculos dentários de grupos de pescadores-coletores do litoral sul do Brasil. Apresenta também os resultados das relações mantidas entre grânulos de amido e cárie, e entre fitólitos e desgaste dentário.

Através da dissolução química de cálculos dentários foram recuperados microvestígios vegetais em todos os indivíduos estudados. Foi evidenciado o consumo de alimentos amiláceos em todas as séries esqueléticas estudadas, demonstrando independência entre dieta com aporte de produtos vegetais e utilização de cerâmica. Foram encontrados resultados sugestivos de padrões de escolha de alimentos diferenciados entre os grupos e evidências de contato entre litoral e planalto.

Palavras-chave: Sambaquis - Pescadores-coletores - Amidos - Fitólitos Cáries - Desgaste.

\section{Introdução}

Cambaquis estão entre os sítios

arqueológicos mais estudados no Brasil.

Gaspar (1998, 2000) refere a presença de 958 desses sítios espalhados pela faixa costeira brasileira entre o sul da Bahia e o norte do Rio Grande do Sul. Os sambaquis mais antigos conhecidos datam de seis milênios antes do presente e já são registros materiais de grupos
(*) Departamento de Endemias Samuel Peixoto/Escola Nacional de Saúde Pública Sérgio Arouca/Fiocruz. V.W. wesowski@woc.com.br ; S.F.M.S. sferraz@ensp.fiocruz.br (**) School of Natural Resources/University of
Nebraska.reinhard@unlserve.unl.edu (***) Laboratório de Anatomia Vegetal/Instituto de Biociências/Universidade de São Paulo.gregorio@usp.br 
humanos bem adaptados ao ambiente costeiro, o que sugere experiência e permanência anteriores em ambiente litorâneo (Gaspar, 1998, 2000).

Os sambaquis já foram considerados o resultado meramente fortuito do acúmulo de restos alimentares (Wierner 1876) ou o resultado intencional do descarte cumulativo de restos alimentares efetuado por motivos práticos como elevar nível do terreno habitado (Prous 1991). Atualmente são entendidos como construções feitas com intencionalidade e propósito ao longo de muitas gerações (Gaspar 1998; Afonso 1999; Fish et al 2000).

A porção protéica de sua dieta baseou-se em peixes e moluscos, além de crustáceos e em menor quantidade de mamíferos, havendo variações regionais e temporais quanto às espécies consumidas (Garcia 1972; Lima 1991; Figuti 1992, 1993; Bandeira 1992). Devido às condições de preservação pouco favoráveis e a abordagens de pesquisa inadequadas, o conhecimento atual sobre o uso e consumo de vegetais por sambaquianos é ainda preliminar.

O relato da preservação pontual de artefatos feitos de madeira e fibras em alguns sítios como Cubatão I (Petrykowski 2006) e Espinheiros II (Afonso e De Blasis 1994), os trabalhos de antracologia (Scheel-Ybert 2001, 2002a, 2002b), as observações casuais sobre ocorrência de sementes queimadas (Garcia 1972; Goulart 1980; Bryan 1993; Bandeira 2004) sugerem que vegetais eram bem conhecidos e usados por estes grupos. Quanto às plantas comestiveis, a literatura refere apenas Dioscorea sp (carás) e sementes de Arecaceae (palmeiras), de Myrtaceae (araçás) e de Annonaceae (pinha, ata) (Tiburtius, Bigarella e Bigarella 1951; Garcia 1972; Bryan 1993; ScheelYbert 2001, 2002a, 2002b).

Há cerca de dois milênios vários sítios de pescadores-coletores, menos imponentes e com menor impacto na paisagem começaram a surgir (Prous 1991, 2006). São sítios mais rasos, com sedimento mais arenoso, sem o característico acúmulo de conchas, mas com acúmulo de ossos de peixe, e muitas vezes se sobrepuseram a sambaquis típicos constituindo sua camada ocupacional mais recente. Freqüentemente estes sítios são identificados na literatura como os vestígios ocupacionais de grupos diferentes daqueles que construíram os sambaquis (Rohr 1961; Prous 1991, 2006).

A área de ocorrência desse tipo de sítio é sobreposta à dos sambaquis e a evidência arqueológica aponta para grupos igualmente bem adaptados à vida em ambiente litorâneo, tanto do ponto de vista da subsistência como da cultura material, a qual pouco difere daquela encontrada nos sambaquis. A maior diferença encontra-se na ocorrência de anzóis em determinadas regiões e na presença de cerâmica identificada com a tradição Itararé em alguns sítios (Tiburtius, Bigarella e Bigarella 1951; Beck, Araújo e Duarte 1970; Beck 1972; Bandeira 2004). A base protéica da dieta continuou sendo o peixe, embora com menor participação dos moluscos (Bandeira 1992, 2004). A presença de cerâmica levou alguns pesquisadores a considerarem que, pelo menos nestes casos, os grupos já possuiriam algum tipo de horticultura, em oposição aos sambaquianos que seriam apenas pescadores-coletores (Beck 1972, 1974; Chymz 1976; Schmitz 1988). No entanto, o traço mais freqüentemente citado como elemento diferenciador entre estes sítios e os sambaquis, é a falta da elevação e do destaque na paisagem típicos dos sambaquis (Prous 1991, 2006).

Em um modelo inclusivo foi proposto por Gaspar (1998, 2000), a construção de um espaço diferenciado que marca a paisagem, e seu uso concomitante como moradia, cemitério e lugar de acúmulo de restos de fauna representariam um marco de identidade para a cultura sambaquiana, para além das variações regionais. Por este modelo pelo menos alguns dos sítios mais rasos ("acampamentos litorâneos”, Prous 1991) do litoral sul seriam variações locais do sistema sambaquiano. Mesmo diferenciando os "sambaquis strictu senso" dos “acampamentos litorâneos”, Prous (1991) claramente os considerou relacionados, ao menos em determinadas regiões da costa, como no litoral sul. A escolha mais recente da expressão "sítios de pesca e coleta não construídos" utilizada pelo autor (Prous 2006) retira a idéia de pouca permanência envolvida na expressão "acampamentos" anteriormente utilizada. 
Esse modelo de intensiva ocupação do litoral por pescadores-coletores-caçadores que depois teriam sido substituídos por grupos que incluíram a horticultura em suas estratégias de subsistência e estilos de vida levanta a hipótese da ocorrência de uma transição na saúde. Essa transição significaria provavelmente mudança na patocenose (Mendonça de Souza 1999) com possível aumento das prevalências de indicadores inespecíficos de estresse e determinadas patologias tais como cáries e infecções, tal como proposto em Cohen e Armelagos (1984), Goodman et al. (1984a, 1984b), Larsen (1981, 1984), e outros (Rose et al. 1984, Larsen et al. 1990).

Partindo deste cenário, algumas pesquisas analisaram uma série de alterações fisiopatológicas geralmente associadas com o padrão de subsistência, esperando encontrar, grosso modo os marcadores de saúde e, por conseguinte, a patocenose expressando-se diferentemente em grupos sem cerâmica e grupos com cerâmica (Wesolowski 2000; Neves e Wesolowski 2002). Os resultados encontrados, no entanto, não mostraram diferenças claras entre as séries esqueléticas oriundas de sítios com cerâmica e aquelas provenientes de sítios sem cerâmica. Em contrapartida, três séries sem cerâmica mostraram freqüências e prevalências de cáries significativamente mais altas que as esperadas para grupos não horticultores (Wesolowski 2000; 2007).

Dado que a literatura mostra alta correlação entre lesões cariosas e consumo aumentado de alimentos ricos em carboidratos (Turner II 1979, Cohen e Armelagos 1984), foi proposto como hipótese explicativa o aumento do consumo de vegetais por parte dos três grupos em questão, através de horticultura incipiente ou manejo vegetal intensivo. Essa hipótese também apontaria para uma estratégia de subsistência mais complexa do que a habitualmente postulada para os grupos sambaquianos da região. Ao mesmo tempo, a validade da interpretação da presença de cerâmica como indicador de horticultura na região foi questionada (Wesolowski 2000).

No quadro dos conhecimentos atuais sobre os grupos de pescadores-coletores do litoral centro-sul do Brasil é evidente a quantidade limitada de informações disponíveis sobre o uso de vegetais. Por outro lado, a inferência de estratégias de subsistência feitas apenas através da presença ou ausência de traços de cultura material (como a cerâmica), ou do padrão de manifestação de processos fisiopatológicos, não tem sido suficiente para uma aproximação mais exata do que seria o modo de vida desses grupos. A avaliação direta de vestígios vegetais antigos com potencial dietético é fundamental para a compreensão das estratégias de subsistência destes grupos. Considerando-se a escassez de macro-restos vegetais, os micro-resíduos vegetais preservados configuram uma possibilidade de grande potencial informativo.

Desde 1990 as pesquisas que objetivam investigar o espectro vegetal utilizado por grupos humanos pretéritos através da recuperação, da identificação e da análise de microresíduos vêm se tornando mais freqüentes (Piperno 1985; Fox e Pérez-Pérez 1994; Torrence e Barton 2006). Ao longo das duas últimas décadas se multiplicaram os trabalhos sobre fitólitos presentes em amostras de solo, de coprólitos e de artefatos (Loy Spriggs e Wickler 1992; Fox, Juan e Albert 1996; Danielson e Reinhard 1998; Piperno e Holst 1998; Piperno et al. 2000). Grânulos de amido antigos foram igualmente recuperados em uma grande variedade de ambientes e substratos (Reinhard et al. 2001, Barton e Matthews 2006), estando presentes em materiais arqueológicos variados, incluindo alimentos preservados por dessecação e carbonização, artefatos, cálculos dentários e coprólitos, além de amostras de solo (Ugent, Pozorsky e Pozorsky 1986; Loy 1994; Piperno e Holst 1998; Piperno et al. 2000; Van Peer et al. 2003).

Nessa linha, os autores deram início ao estudo de materiais esqueléticos provenientes de sítios do tipo sambaquis com o objetivo de recuperar e analisar micro-resíduos vegetais retidos em cálculos dentários, considerando a possibilidade de identificar amidos e outros indicadores da dieta e de comparar suas ocorrências em sítios com diferentes prevalências de cáries. Foram utilizadas as séries esqueléticas 
anteriormente estudadas quanto à patologia dentária pela primeira autora (Wesolowski 2000, 2007). A partir da recuperação desses micro-vestígios, procurou-se estabelecer a recorrência de uso e a variabilidade de vegetais amiláceos empregados na alimentação, bem como a relação entre quantidade de grânulos de amido presentes nos cálculos dentários e prevalências/freqüências de cáries nas séries, assim como a relação entre a quantidade de fitólitos e as características dos desgastes dentários observados.

\section{Material}

O litoral norte de Santa Catarina concentra um grande número de sítios de pescadorescoletores (Bandeira 2004; Oliveira 2000), numa área que é um mosaico geomorfológico e de vegetações, formando um rico ecótone litorâneo com ambientes lacustres, estuarinos, pequenas lagoas e baías de fundo lodoso e arenoso, praias de mar aberto, costões, mangue, mata de restinga e mata Atlântica (Oliveira 2000).

As datações mais antigas para a ocupação local por grupos sambaquianos típicos estão em torno de 4800 anos BP para o Rio Comprido (Prous 1977). Este período corresponde a um momento em que o mangue, mais rarefeito, iniciava sua expansão acompanhando a regressão marinha, desse modo, apenas os sítios mais recentes são contemporâneos de amplas áreas de manguezais plenamente desenvolvidos (Oliveira 2000). Da mesma maneira, o início da expansão da floresta de araucária ao longo dos vales dos rios a partir de 3000 anos BP e sua plena expansão na região serrana do norte de Santa Catarina há 1000 anos BP (Behling 1998, 2001), tornou disponível para exploração no período mais recente de ocupação da área um novo ecossistema localizado a poucos quilômetros de distância da região.

O registro arqueológico da região fornece indícios de continuidade para características biológicas, econômicas, funerárias e de cultura material por quase cinco milênios até a chega- da dos europeus. Apesar disto, está claro que por volta de 1000 anos BP houve a introdução de cerâmica e de um contingente populacional biologicamente distinto (Mello Alvim 1978; Neves 1988; Neves e Blum 1998; Bandeira 2004; Hübbe 2005). O processo pelo qual tais mudanças ocorreram ainda não foi satisfatoriamente compreendido, mas aspectos da geografia e paleogeografia locais sugerem que a região apresentaria características facilitadoras para o contato com o interior e com a região da Baía de Paranaguá (Oliveira 2000).

Considerando este cenário, alguns sítios arqueológicos já escavados para esta região apresentam coleções numericamente expressivas, que foram escolhidas para o presente trabalho, correspondendo aos sambaquis Morro do Ouro, Enseada, Forte Marechal Luz e Itacoara, todos localizados na região da Baía da Babitonga, Santa Catarina. Estes sítios já haviam sido estudados anteriormente para cárie e outros indicadores de saúde (Wesolowski 2000; Neves e Wesolowski 2002), tendo sido agora revisados para indicadores dentários e analisados para o conteúdo dos micro-resíduos em cálculos dentários (Wesolowski 2007).

Os esqueletos compõem cinco séries esqueléticas diferentes, três não associadas com cerâmica e duas associadas a sítios ou camadas arqueológicas com cerâmica (Tabela 1). O material encontra-se sob guarda do Museu Arqueológico de Sambaqui de Joinville MASJ (Morro do Ouro, Enseada 1 e Itacoara) e do Museu Nacional/Universidade Federal do Rio de Janeiro - MN-UFRJ (Forte Marechal Luz).

As séries para estudo foram constituídas por todos os indivíduos que cumpriram os seguintes critérios de inclusão: a existência de procedência estratigráfica segura e a presença de dentes confiavelmente assignados ao indivíduo. Embora como regra apenas um cálculo de cada indivíduo tenha sido utilizado para a recuperação de micro-resíduos, nos casos em que foi constatada a presença de desgaste para-mastigatório foram coletados e analisados mais de um cálculo. Os totais de indivíduos e cálculos utilizados para a recuperação de micro-resíduos em cada série são: 
Tabela 1

\begin{tabular}{|c|c|c|c|}
\hline \multicolumn{4}{|c|}{ Séries utilizadas na pesquisa e respectivas datações } \\
\hline Sítios & Série & Datação & $\begin{array}{l}\text { Identificação da } \\
\text { amostra datada }\end{array}$ \\
\hline \multicolumn{4}{|c|}{ Sem cerâmica } \\
\hline Morro do Ouro & MO-REC & $\begin{array}{l}\text { Em processo de datação } \\
\text { no momento }\end{array}$ & $* * * * * * * * * * * * *$ \\
\hline Morro do Ouro & MO-ANT & $\begin{array}{l}4030 \pm 40 \text { anos BP } \\
\text { (Wesolowski 2000) }\end{array}$ & $\begin{array}{l}\text { C14, colágeno, sepultamento } 28 . \\
\text { Beta analytics Inc, Beta - } 93152\end{array}$ \\
\hline Forte Marechal Luz & FML-SCR* & $\begin{array}{l}1110 \pm 100 \text { anos BP e } \\
850 \pm 100 \text { anos BP } \\
\text { (Bryan 1993) }\end{array}$ & $\begin{array}{l}\text { C } 14 \text {. Respectivamente } \\
\text { sementes carbonizadas e } \\
\text { carvão, em ambos os casos } \\
\text { associados a sepultamentos. }\end{array}$ \\
\hline \multicolumn{4}{|c|}{ Com cerâmica } \\
\hline \multirow{2}{*}{$\begin{array}{c}\text { Enseada } 1 \\
\text { Itacoara }\end{array}$} & \multirow{2}{*}{$\begin{array}{c}\text { Enseada } 1 \\
\text { Itacoara }\end{array}$} & $\begin{array}{l}1390 \pm 40 \text { anos BP } \\
\text { (De Mais 2001) }\end{array}$ & $\begin{array}{l}\text { C14, colágeno, esqueleto } \\
\text { humano. }\end{array}$ \\
\hline & & $\begin{array}{l}550 \pm 55 \text { anos BP (?) } \\
(\text { Bandeira 2004)** }\end{array}$ & Termoluminescência, cerâmica. \\
\hline
\end{tabular}

*Forte Marechal Luz-Sem CeRâmica. ** Datação dada pela autora como duvidosa.

MO-REC, 6 indivíduos e 6 cálculos, MO-ANT, 8 indivíduos e 8 cálculos; Enseada 1, 17 indivíduos e 21 cálculos; FML-SCR, 4 indivíduos e 7 cálculos; Itacoara, 11 indivíduos e 11 cálculos.

Características dos sítios e séries esqueléticas analisadas são apresentadas a seguir de maneira sintética tendo em vista os objetivos deste estudo.

O Sambaqui Morro do Ouro é localizado ao fundo da Baía da Babitonga, município de Joinville, à margem do Rio Cachoeira (Oliveira 2000), e está entre os sítios de grandes dimensões da área e pode ser considerado um representante típico da ocupação sambaquiana da região. Os diversos trabalhos publicados descrevem a presença de muitas camadas lenticulares de carvão, sementes queimadas de Syagrus romanzoffiana (jerivá) e fogueiras (Beck, Duarte e Reis 1969; Beck 1972; Prous 1977; Goulart 1980; Tiburtius 1996).

O número total de esqueletos exumados no sítio é de, pelo menos, 116 indivíduos, sendo 15 indivíduos oriundos da escavação de
Guilherme Tiburtius (1996), 12 da escavação de Anamaria Beck (Beck, Duarte e Reis 1969; Beck 1972) e 89 da escavação de Marilandi Goulart (1980). Embora a relação estratigráfica segura entre as diversas séries esqueléticas escavadas no sítio não seja possível, as descrições disponíveis para as diversas escavações indicam a existência de pelo menos dois cemitérios temporalmente distintos (Wesolowski 2002; 2007).

Apenas parte dos sepultamentos escavados por Marilandi Goulart pôde ser estudada. Os indivíduos foram separados em duas séries esqueléticas distintas segundo a posição estratigráfica das sepulturas (Wesolowski 2000; 2007): Morro do Ouro recente (MO-REC) e Morro do Ouro antiga (MO-ANT), analisadas independentemente. As séries esqueléticas MOREC e MO-ANT formam um conjunto homogêneo e são caracterizadas por freqüências de dentes afetados por cáries altas, respectivamente $8,85 \%$ e $8,24 \%$, e prevalências também altas, com expressão positiva da doença em metade dos indivíduos das séries, sendo alguns mais gravemente afetados. Ocorrem cáries de raiz e de 
colo, além das oclusais, e também exposição de câmara pulpar por processo carioso. Os cálculos dentários são pequenos, em geral limitados ao contorno gengival, pouco densos, freqüentemente friáveis e frouxamente aderidos aos dentes. A coloração é amarelada clara e ocorreu pouco ou nenhum sedimento macroscópico aderido. As freqüências de dentes afetados por cálculo são moderadas, respectivamente $51,15 \%$ e $65,88 \%$. Ambas as séries apresentam mulheres ligeiramente mais afetadas por cáries e homens ligeiramente mais afetados por cálculos dentários e com tendência a apresentarem depósitos um pouco maiores. $\mathrm{O}$ desgaste é moderado em ambas as séries. A fração feminina da série MO-REC apresenta desgaste ligeiramente mais leve que os homens, enquanto que as mulheres da série MO-ANT apresentam desgastes mais intensos que os homens (Wesolowski 2007).

O Sambaqui Enseada 1 está localizado no noroeste da Ilha de São Francisco do Sul, sobre um afloramento rochoso voltado diretamente para mar aberto ao leste. Os trabalhos publicados descrevem a existência de duas camadas ocupacionais distintas, com presença de fogueiras e lentes de sementes queimadas de Syagrus romanzoffiana, algumas das quais com até $0,50 \mathrm{~m}$ de espessura (Beck 1972, 1974; Prous 1977; Tiburtius 1996). Apesar de a ocupação sazonal de inverno ter sido sugerida para ambas as camadas (Beck 1972, 1974), ocorrem evidências claras de ocupação de ano todo (Bandeira1992; Prous 1977). Por outro lado, a camada mais recente apresenta preponderância de recursos de verão, sugerindo a possibilidade de armazenamento de alimentos ou de deslocamento parcial da população durante o inverno (Bandeira 1992).

A maior diferença no conjunto artefactual das duas camadas é a cerâmica Itararé, presente apenas na camada superior e semelhante àquela encontrada em Forte Marechal Luz (Beck 1972, 1974). Resíduos de lipídio extraídos de fragmentos de cerâmica e analisados por cromatografia gasosa e cromatografia gasosa-espectrometria de massa foram identificados como gordura animal degradada, freqüentemente de origem marinha, e compostos lipídicos vegetais (ceras epicutilares e a resinas) (Hansel e Schmitz 2006).

Foram escavados no sítio pelo menos 66 esqueletos. Destes, 46 são oriundos da escavação de Tiburtius (1996) e foram todos recuperados da camada cerâmica. Outros 22 foram escavados por Beck (1972, 1974), sendo dez na camada inferior e dez na camada superior.

Foram estudados apenas os indivíduos exumados por Guilherme Tiburtius, coleção escolhida devido ao maior número de indivíduos. A série Enseada 1 apresenta prevalência e freqüência de dentes afetados por cárie baixas, respectivamente $10 \%$ e $1,64 \%$, com ocorrência apenas de lesões oclusais. Somente os indivíduos masculinos apresentaram cáries. Os cálculos são de tamanho mediano a pequeno, limitados às superfícies lingual e bucal, e não recobrem completamente a coroa. Por vezes estendem-se para superfícies radiculares quando estas se encontravam expostas ao ambiente bucal. Estão bem aderidos aos dentes, mas soltam-se facilmente quando submetidos à pressão. A coloração é acastanhada clara, são densos, pouco friáveis e apresentaram pouco sedimento macroscópico aderido. A freqüência de cálculo dentário é elevada com 79,69\% dos dentes afetados, sendo os dentes da fração masculina mais afetados por cálculos em relação àqueles da fração feminina. $\mathrm{O}$ tamanho dos depósitos também tende a ser maior entre os homens. O desgaste dentário é predominantemente severo com ocorrência de desgaste para-mastigatório de plano helicoidal nos dentes posteriores em alguns indivíduos. A fração masculina é ligeiramente mais afetada por desgaste severo que a fração feminina (Wesolowski 2007).

O Sambaqui do Forte Marechal Luz está localizado no norte da Ilha de São Francisco do Sul, na entrada da Baía da Babitonga, a meia encosta do Morro São João, e teria sido continuamente ocupado por um mesmo grupo. Restos vegetais estiveram presentes em todas as camadas, principalmente sementes e cascas de frutos de Arecaceae (palmeiras), de Sapotaceae, 
de Myrtaceae e de Myristicaceae (Bryan 1993). A continuidade da maioria dos aspectos da cultura material, da economia e do ritual funerário e a falta de indícios estratigráficos de quebra no contínuo deposicional sugerem que Forte Marechal Luz seja o resultado da ocupação de um mesmo e único grupo, o qual teria ampliado seu repertório artefactual e incorporado novas técnicas no período mais recente de ocupação do sítio. $\mathrm{O}$ aparecimento da cerâmica em quantidade elevada nas camadas mais recentes e o pleno domínio da técnica oleira, aliados à permanência de traços culturais que já estavam presentes, seriam igualmente argumentos favoráveis à continuidade de ocupação (Bryan 1993).

Foram evidenciados 65 sepultamentos, sendo 42 localizados em estratos sem cerâmica e 23 em estratos com cerâmica, porém, nem todas as sepulturas registradas tiveram os ossos recolhidos. Entre os esqueletos recuperados foram identificados 79 indivíduos, a maioria em mau estado de preservação, sendo 26 crianças com menos que 5 anos (Mello e Alvim e Mello Filho 1967-68; Bryan 1993).

Apenas os indivíduos exumados nas camadas sem cerâmica puderam ser estudados, os quais formaram a série FML-SCR. A série FML-SCR apresenta prevalência e freqüencia de dentes afetados por cárie baixas, respectivamente $22,22 \%$ e $1,85 \%$, com ocorrência exclusiva de lesões oclusais e apenas homens afetados. Os cálculos são predominantemente moderados mas tendendo a grandes, em alguns casos recobrem todo o dente, incluindo superfícies oclusais e radiculares. Apresentam-se muito densos, muito duros e fortemente aderidos ao dente, sendo a coloração mais freqüente o acastanhado escuro. Ocorre sedimento macroscópico aderido em quantidade maior que nas demais séries. A freqüência de cálculo dentário é elevada, com 73,58\% dos dentes afetados, e homens mais acometidos que mulheres. $\mathrm{O}$ tamanho dos depósitos de cálculo é semelhante em ambos os sexos. O desgaste dentário é predominantemente severo com os homens mais afetados por desgastes desta intensidade que as mulheres (Wesolowski 2007).
O sítio Itacoara, com cerâmica Itararé, está localizado na meia-encosta de uma elevação cristalina isolada em meio à planície sedimentar periodicamente inundada e dista $30 \mathrm{~km}$ da linha de costa (Tiburtius, Bigarella e Bigarella 1951; Bandeira 2004). Pouco elevado em relação ao terreno adjacente e sem os aspectos de visibilidade e destaque na paisagem típicos dos sambaquis, apresenta duas camadas ocupacionais, a superior, mais terrosa, semelhante aos acampamentos litorâneos, e a inferior semelhante a um sambaqui fluvial (Tiburtius, Bigarella e Bigarella 1951; Bandeira 2004). Apesar da ocorrência de grande quantidade de restos vegetais em ambas as camadas, estes são mais freqüentes na camada superior. São comuns as sementes carbonizadas de Arecaceae, principalmente de Butia sp (butiá) e Syagrus romanzoffiana, (Tiburtius, Bigarella e Bigarella 1951; Bandeira 2004).

O repertório artefactual é semelhante em ambas as camadas, no entanto apenas a camada superior apresentou cerâmica, identificada como Itararé. Também apenas na camada superior foram recuperados artefatos confeccionados em matérias-primas originárias do planalto (Tiburtius, Bigarella e Bigarella 1951; Beck 1971; Piazza 1974; Bandeira 2004).

No total foram evidenciadas 57 sepulturas no sítio, porém apenas 32 esqueletos foram recuperados, sendo 28 oriundos da escavação de Guilherme Tiburtius e 4 da escavação de Dione Bandeira (Tiburtius, Bigarella e Bigarella, 1951; Bandeira, 2004).

Foram estudados apenas os indivíduos exumados por Guilherme Tiburtius, coleção escolhida devido ao maior número de indivíduos. A série Itacoara apresenta prevalência e freqüência de dentes afetados por cárie baixas, respectivamente 11,54 e $1,27 \%$. Ocorrem apenas lesões oclusais, estando a cárie restrita à fração feminina. Os cálculos possuem tamanho em geral pequeno mas tendendo a moderados, limitados às superfícies lingual e bucal, e não recobrem a coroa embora por vezes estendamse para superfícies radiculares. Estão bem aderidos aos dentes, mas soltam-se facilmente quando submetidos à pressão. A coloração é acastanhada clara, são densos, pouco friáveis e apresentam pouco sedimento macroscópico 
aderido. A freqüência de cálculo dentário é baixa com apenas $47,97 \%$ dos dentes afetados. As mulheres são ligeiramente mais afetadas que os homens e os depósitos de cálculo têm tamanho semelhante em ambos os sexos. $\mathrm{O}$ desgaste dentário é predominantemente leve com ocorrência de desgaste para-mastigatório de plano helicoidal nos dentes posteriores em alguns indivíduos. A fração feminina da série tende a ter desgaste ligeiramente mais leve que a fração masculina (Wesolowski 2007).

Maiores detalhes da arqueologia dos sítios e características da fisiopatologia dentária podem ser encontradas na literatura específica e em Wesolowski (2007).

\section{Métodos}

Os procedimentos técnicos da pesquisa foram adaptados a partir de protocolos para extração e análise de resíduos em cálculos dentários humanos (Fox, Juan, Albert 1996; Walshaw 1999; Reinhard et al. 2001) baseadas no protocolo de Middleton (1990) para recuperação de micro-resíduos em cálculos de herbívoros, o qual por sua vez é uma adaptação de protocolo publicado por Armitage (1975), igualmente para herbívoros.

A coleta dos cálculos foi feita, após a análise de patologias dentárias (Wesolowski 2007), nas instituições de origem dos acervos, MN-UFRJ e MASJ, evitando-se o deslocamento dos materiais arqueológicos. Para diminuir o risco de contaminação por micro-resíduos modernos presentes no ambiente, em ambos os laboratórios foi isolada uma bancada para o trabalho. Essa área de trabalho foi limpa diariamente com hipoclorito de sódio e água, aplicados e removidos com esponja de espuma sintética, evitando-se o uso de papel e tecido por serem materiais ricos em fibras. Sempre que houve um intervalo entre coletas, o procedimento de limpeza foi repetido. As portas dos laboratórios foram mantidas fechadas e as janelas, no caso do laboratório do MASJ, fechadas e lacradas com fita adesiva. Foram utilizadas luvas descartáveis de látex sem pó durante a extração.
Após a limpeza do dente e do cálculo com escova interdental macia descartável, hipoclorito de sódio e água destilada, cada cálculo foi destacado do dente e armazenado individualmente em um micro-tubo de centrífuga estéril com capacidade para $1,5 \mathrm{ml}$.

Cada cálculo coletado recebeu um número de amostra seqüencial registrado em um caderno de controle de amostras. Cerca de 1/ 3 de cada cálculo foi separado e reservado para controle ou análises futuras. Os $2 / 3$ destinados à dissolução química foram pesados em balança com precisão de três casas decimais. Nos casos em que os cálculos eram leves demais para esta precisão, o peso foi registrado por aproximação como 0,0009.

A extração dos micro-resíduos foi feita no laboratório de palinologia e paleoparasitologia da School of Natural Resources, University of Nebraska at Lincoln (SNR-UNL) e seguiu o protocolo desenvolvido para esse fim. Nenhum outro material foi manipulado no laboratório concomitantemente aos cálculos. Uma bancada do laboratório foi isolada para o trabalho com os cálculos e tanto a bancada como a capela utilizadas foram limpas com hipoclorito de sódio diariamente. Toda a vidraria utilizada foi previamente esterilizada por imersão em peróxido de hidrogênio $50 \%$ durante três horas. A lavagem pós-imersão foi feita com água destilada.

Cálculos coletados de duas séries esqueléticas diferentes não foram processados concomitantemente. Para evidenciar uma possível contaminação durante o processo de extração foram constituídas e processadas amostras controle compostas exclusivamente por um tablete de esporos de Lycopodium. ${ }^{1}$ Estes controles foram processados em tubos de centrífuga de $12 \mathrm{ml}$, de vidro, fechados com parafilme. $\mathrm{O}$ número de controles variou entre um e três por série, no total de 14 amostras controles.

O processamento dos cálculos foi feito em micro-tubos devido ao tamanho reduzido

(1) Batch $n^{\circ} 212761$, aproximadamente 12489 esporos por tablete. 
das amostras. Os micro-tubos foram mantidos abertos apenas pelo tempo necessário para o acréscimo ou descarte das substâncias químicas utilizadas no processamento. Para possibilitar o cálculo da concentração de micro-resíduos por grama de cálculo dentário (Warnock e Reinhard 1992; Reinhard et al. 2001) um tablete de esporos de Lycopodium foi adicionado a cada micro-tubo contendo uma amostra de cálculo dentário.

Os cálculos foram dissolvidos por imersão em ácido clorídrico 10\% (HCL 10\%) pelo tempo necessário a sua completa dissolução, centrifugados para descarte do ácido, lavados com água destilada, centrifugados para descarte da água e desidratados com etanol 100 PA (ETOH $100 \mathrm{PA})$.

Para controlar a possibilidade de descarte parcial das amostras junto com o sobrenadante, todo o HCL e a água destilada descartados de cada conjunto de amostras em processamento foram recolhidos em um tubo de vidro com fundo cônico e $12 \mathrm{ml}$ de volume e centrifugados. O conteúdo do tubo foi inspecionado apenas visualmente procurando-se por resíduos depositados no fundo. O sobrenadante descartado de ETOH 100PA foi tratado da mesma forma, exceto por ter sido inspecionado ao microscópio de luz como meio de verificar se houve perda de material das amostras durante o descarte.

Todas as amostras de cálculo e de controle tiveram o volume de ETOH 100PA reduzido para $0,5 \mathrm{ml}$. Foi montada uma lâmina para cada amostra de cálculo e a totalidade dos $0,5 \mathrm{ml}$ de líquido de cada amostra controle de Lycopodium. Foi utilizado glicerol puro como meio de montagem para preservar a mobilidade e resina termo-ativada Meltmount 1,539 (Cargille) como selador da montagem. Foram usadas lâminas e lamínulas ( $24 \times 32)$ pré-limpas e estéreis da marca comercial Gold Seal e ponteiras para pipetador automático com baixa retenção, estéreis e descartáveis (uma para cada montagem de lâmina).

A observação das lâminas foi feita no laboratório de Anatomia Vegetal do Instituto de Biociências, da Universidade de São Paulo (IB-USP). Todas as lâminas foram observadas ao microscópio de luz transmitida com uso de luz polarizada e filtro de interferência lambda quando necessário à observação de grânulos de amidos. As lâminas foram varridas em aumento de 400 vezes (objetiva 40x e ocular 10x). Foi aplicada, com o auxílio de um estilete, leve pressão sobre a lamínula para provocar a movimentação do micro-resíduo, sempre que necessária a observação de formas tridimensionais (amidos e fitólitos).

Além dos amidos e fitólitos, foram também contados e fotografados areia, fragmentos escuros (FGE) (possivelmente carvão) e esporos de Lycopodium. A identificação destes micro-resíduos foi feita apenas através de aspectos morfológicos e óticos, sem utilização de coloração.

A concentração individual por grama de cálculo, de cada um dos quatro tipos de micro-resíduo, foi calculada segundo a seguinte formula (Pearsall 2000; Warnock e Reinhard 1992):

\section{concentração $=(T m C / T L C) T L A d$ peso do calculo}

\section{Onde:}

$. \mathrm{TmC}=$ Total de ocorrências contadas de um determinado micro-resíduo (p.ex. amido);

. TLC $=$ Total de esporos de Lycopodium contados;

. TLAd $=$ Total de esporos de Lycopodium adicionados;

. Peso do cálculo $=$ Peso em gramas do cálculo.

As concentrações médias de grânulos de amido e de fitólitos foram comparadas entre as séries. Foram testadas as correlações mantidas entre concentração de grânulos de amido e número de lesões cariosas, bem como concentração de fitólitos e intensidade do desgaste dentário.

A descrição detalhada de todos os procedimentos metodológicos aplicados e a discussão da sua eficácia podem ser encontradas em Wesolowski (2007). 


\section{Resultados}

Não houve qualquer perda amostral durante os descartes. Nenhum dos 14 controles de Lycopodium apresentou amidos, fitólitos, areia ou FGE, tendo sido encontrados além de esporos de Lycopodium apenas fibras de diversos tipos em ocorrência eventual.

Foram encontrados grânulos de amidos, fitólitos, areia e FGE em todos os cálculos analisados. Os valores das contagens absolutas e das concentrações de cada micro-resíduo variaram internamente em todas as séries (Tabela 2).
Além de amidos, fitólitos, areia e FGE, foram freqüentemente encontrados nas lâminas possíveis cristais de cálcio e estruturas sugestivas de epiderme vegetal, além de fibras de vários tipos em ocorrência eventual e fragmentos de matriz do cálculo. As séries MO-REC e MO-ANT apresentaram menor diversidade de formas de grânulos de amidos e de fitólitos, enquanto as demais séries apresentaram maior variabilidade de formas tanto de grânulos de amido como de fitólitos. Exemplos dos microresíduos encontrados em cada série estão nas Figuras 1 e 2.

Tabela 2

Caracterização dos indivíduos e amostras de cálculos analisados e concentrações de micro-resíduos calculadas

\begin{tabular}{ccccccc}
\hline \multirow{2}{*}{ Série } & $\begin{array}{c}\text { Número do } \\
\text { Indivíduo }\end{array}$ & $\begin{array}{c}\text { Peso do cálculo } \\
\text { em gramas }\end{array}$ & \multicolumn{3}{c}{ Concentrações por grama de cálculo } \\
\cline { 4 - 7 } & & & Amido & Fitólito & Areia & FGE \\
\hline \hline MO-REC & 8 & 0,0009 & 58.871 & 0 & 16.820 & 8.410 \\
MO-REC & 2 & 0,010 & 8.390 & 8.390 & 31.163 & 22.773 \\
MO-REC & 80 & 0,0009 & 81.388 & 27.129 & 284.858 & 67.834 \\
MO-REC & 60 a & 0,0009 & 64.996 & 10.833 & 0 & 10.833 \\
MO-REC & $60 \mathrm{~B}$ & 0,001 & 24.250 & 0 & 0 & 24.250 \\
MO-REC & 10 & 0,070 & 401 & 802 & 401 & 401 \\
MO-ANT & $44 \mathrm{~B}$ & 0,008 & 9.912 & 0 & 0 & 4.956 \\
MO-ANT & 29 & 0,009 & 11.655 & 0 & 0 & 0 \\
MO-ANT & 50 & 0,028 & 32.499 & 0 & 768 & 1.280 \\
MO-ANT & 51 & 0,013 & 9.136 & 2108 & 0 & 6.325 \\
MO-ANT & 23 & 0,002 & 76.285 & 10.898 & 10.898 & 10.898 \\
MO-ANT & 28 & 0,001 & 211.402 & 0 & 97.570 & 146.355 \\
MO-ANT & 25 & 0,0009 & 210.892 & 10.545 & 0 & 42.178 \\
MO-ANT & 22 & 0,009 & 9.882 & 0 & 5.647 & 11.293 \\
Enseada 1 & 8529 & 0,022 & 2.110 & 5.276 & 12.662 & 0 \\
Enseada 1 & 8530 & 0,014 & 3.431 & 1.716 & 0 & 0 \\
Enseada 1 & 8532 & 0,010 & 10.352 & 5.176 & 15.528 & 90.950 \\
Enseada 1 & 8636 & 0,007 & 8.156 & 0 & 0 & 0 \\
Enseada 1 & 8693 & 0,003 & 13.216 & 2.643 & 0 & 0 \\
Enseada 1 & 8693 & 0,003 & 26.315 & 60.524 & 47.367 & 0 \\
Enseada 1 & 8703 & 0,015 & 4.664 & 2.332 & 9.329 & 0 \\
Enseada 1 & 8704 & 0,005 & 28.201 & 4.029 & 4.029 & 0 \\
Enseada 1 & 8533 & 0,007 & 25.058 & 7.517 & 0 & 0 \\
Enseada 1 & 8534 & 0,052 & 2.415 & 0 & 0 & 0 \\
Enseada 1 & 8623 & 0,014 & 8.876 & 2.219 & 0 & 0 \\
Enseada 1 & 8634 & 0,012 & 698 & 5.580 & 2.790 & 0 \\
\hline
\end{tabular}


Tabela 2 (cont.)

\begin{tabular}{|c|c|c|c|c|c|c|}
\hline \multicolumn{7}{|c|}{$\begin{array}{l}\text { Caracterização dos indivíduos e amostras de cálculos analisados e } \\
\text { concentrações de micro-resíduos calculadas }\end{array}$} \\
\hline \multirow[t]{2}{*}{ Série } & \multirow{2}{*}{$\begin{array}{l}\text { Número do } \\
\text { Indivíduo }\end{array}$} & \multirow{2}{*}{$\begin{array}{l}\text { Peso do cálculo } \\
\text { em gramas }\end{array}$} & \multicolumn{4}{|c|}{ Concentrações por grama de cálculo } \\
\hline & & & Amido & Fitólito & Areia & $F G E$ \\
\hline Enseada 1 & 8634 & 0,020 & 4.219 & 0 & 0 & 0 \\
\hline Enseada 1 & 8647 & 0,004 & 11.533 & 16.476 & 0 & 0 \\
\hline Enseada 1 & 8647 & 0,017 & 1.453 & 7.267 & 1.453 & 0 \\
\hline Enseada 1 & 8681 & 0,010 & 9.600 & 1.745 & 0 & 0 \\
\hline Enseada 1 & 8681 & 0,020 & 3.171 & 317 & 634 & 0 \\
\hline Enseada 1 & $8638 \mathrm{JV}$ & 0,007 & 16.157 & 2.308 & 0 & 0 \\
\hline Enseada 1 & Sn2 & 0,0009 & 118.689 & 39.563 & 29.672 & 0 \\
\hline Enseada 1 & 8680 & 0,001 & 61.371 & 30.686 & 10.229 & 0 \\
\hline Enseada 1 & $8638 \mathrm{AD}$ & 0,005 & 27.940 & 8382 & 0 & 0 \\
\hline FML-SCR & 6 & 0,004 & 9.376 & 12.502 & 12.502 & 75.009 \\
\hline FML-SCR & 10 & 0,029 & 4.763 & 2.382 & 2.382 & 9.129 \\
\hline FML-SCR & 10 & 0,075 & 827 & 2.481 & 2.481 & 34.600 \\
\hline FML-SCR & 22 & 0,009 & 10.194 & 5.097 & 5.097 & 12.743 \\
\hline FML-SCR & 23 & 0,014 & 4.433 & 0 & 0 & 30.474 \\
\hline FML-SCR & 23 & 0,004 & 11.963 & 0 & 0 & 40.673 \\
\hline FML-SCR & 23 & 0,012 & 3.691 & 2.460 & 2.460 & 18.453 \\
\hline Itacoara & 11 & 0,0009 & 116.968 & 10.633 & 10.633 & 106.335 \\
\hline Itacoara & 21 & 0,003 & 14.388 & 0 & 0 & 9.592 \\
\hline Itacoara & 27 & 0,010 & 9.220 & 838 & 838 & 29.337 \\
\hline Itacoara & 13 & 0,005 & 19.514 & 29.271 & 29.271 & 14.636 \\
\hline Itacoara & 34 & 0,010 & 4.509 & 10.520 & 10.520 & 6.012 \\
\hline Itacoara & $25 \mathrm{~A}$ & 0,024 & 3.082 & 6.678 & 6.678 & 4.110 \\
\hline Itacoara & 12 & 0,004 & 25.033 & 0 & 0 & 6.827 \\
\hline Itacoara & 29 & 0,010 & 2.386 & 795 & 795 & 0 \\
\hline Itacoara & 26 & 0,0009 & 62.019 & 62.019 & 62.019 & 155.047 \\
\hline Itacoara & $25 B$ & 0,003 & 65.633 & 3.125 & 3.125 & 31.254 \\
\hline Itacoara & 31 & 0,028 & 2.625 & 875 & 875 & 11.669 \\
\hline
\end{tabular}

Considerando a variação morfológica dos amidos recuperados pode-se sugerir a presença de grânulos do tipo milho, grânulos do tipo batata doce/Araceae e grânulos de Dioscorea sp, além da presença de grânulos que não se encaixam nessas categorias ou estão muito alterados para que possam ser identificados.

Quanto aos fitólitos, embora a maioria seja de Poaceae, ocorreram formas sugestivas de Arecaceae e uma forma esférica de superfície rugosa que observações iniciais sugerem que possa estar relacionada a sementes de Araucaria angustifolia (pinhão).
A distribuição tanto das formas de amido como de fitólito não foi idêntica em todas as séries. Enseada 1 e Itacoara apresentaram amidos do tipo milho mais freqüentemente, enquanto que grânulos de amido de Dioscorea sp estiveram presentes apenas em MO-REC e MO-ANT. Fitólitos de Poaceae foram encontrados em todas as séries, mas o tipo possivelmente relacionado a pinhão ocorreu apenas em Itacoara e Enseada 1. Grânulos de amido sugestivos de pinhão foram encontrados nas séries FML-SCR; Enseada 1 e Itacoara, mas não em MO-REC e MO-ANT. 


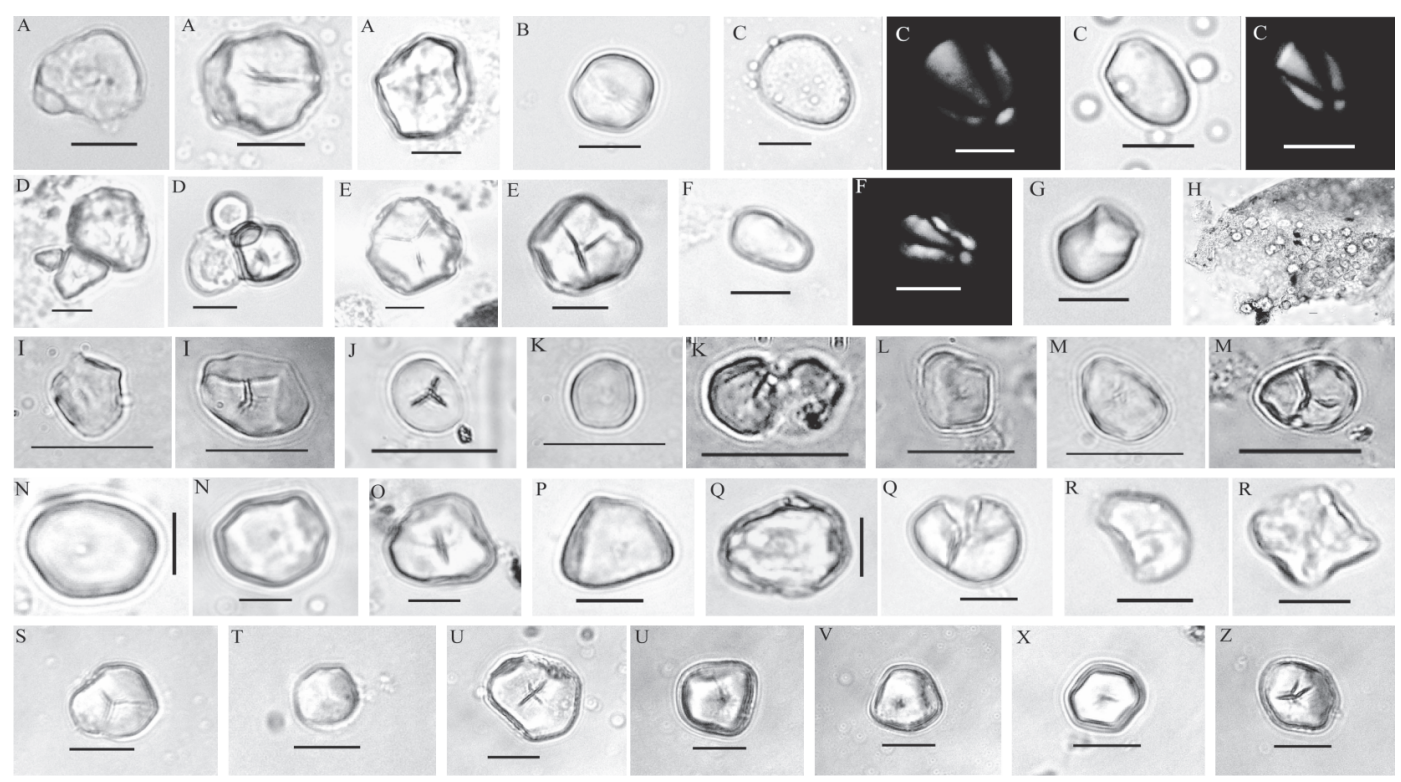

Fig. 1. Exemplos de grânulos de amido encontrados nos cálculos. Todas as barras de escala possuem $20 \mu \mathrm{m}$, exceto em Enseada 1(30 $\mu \mathrm{m})$. MO-REC: A. Possivelmente batata doce, modificados; B. Araceae; C. Dioscorea sp, sob luz normal e polarizada. MO-ANT: D. Aglomerados de amido modificado, não identificados; E. Possivelmente batata doce; F. Dioscorea sp sob luz normal e polarizada; G. Amido não identificado; H. Fragmento de epiderme vegetal com amidos sugestivos de batata doce. Enseada 1: I. Possivelmente pinhão; J. Amido sugestivo de milho, alterado; K. Possivelmente Araceae, alterados; L. Possivelmente batata doce, modificado; M. Não identificados, modificados. FML-SCR: N. Possivelmente Araceae; O. Possivelmente batata doce; P. Não identificado; Q. Não identificados, modificados; R. Sugestivos de pinhão. Itacoara: S. Não identificado; T. Araceae; U. Possivelmente batata doce; V. Não identificado; X. Sugestivo de milho; Z. Possivelmente pinhão.

As comparações das concentrações médias de amido e de fitólitos nas séries através de ANOVA e teste de Wilcoxon não encontraram diferenças estatísticas significativas para $\alpha 0,05$, sugerindo que as variações verificadas entre as séries para as concentrações médias destes micro-resíduos podem estar ocorrendo ao acaso.

Um padrão de relação não linear entre as concentrações de micro-resíduos e o peso em gramas dos cálculos ocorreu em todas as séries. Em todos os casos foi verificada uma relação inversa na qual quanto mais leve o cálculo, maior seu conteúdo de micro-resíduos. Análises de Correlação de Pearson e de Spearman, feitas sobre o total dos cálculos analisados demonstraram a existência de correlações negativas significativas tanto para o par concentração de amido-peso $g\left(\mathrm{R}^{2}\right.$ 0,483316 $p<0,0001 ; \mathrm{R}_{\mathrm{S}}-0,8161$ $p<0,0001$ ), como para o par concentração de fitólitos-peso g $\left(R^{2} 0,19712\right.$ p <0,0001; $\mathrm{R}_{\mathrm{s}}-0,3123$ p 0,0228).

As possíveis associações entre as concentrações de amidos e fitólitos e a ocorrência de cáries e desgaste foram testadas por análise de correlação. Quando considerados na análise de correlação apenas os valores de contagem de lesões cariosas e de concentração de amidos dos indivíduos positivos para cárie, ocorre correlação positiva e significativa entre maior número de lesões cariosas e maior concentração de grânulos de amido, indicando que os indivíduos com maior número de lesões são os mesmos que tendem a ter maiores concentrações de amido $\left(R^{2} 0,835882\right.$ p <0,0001; R 0,8476 p 0,0010). Análise de correlação semelhante feita entre maiores concentrações de fitólito e ocorrência de desgaste dentário severo não demonstrou correlação significativa. 
A
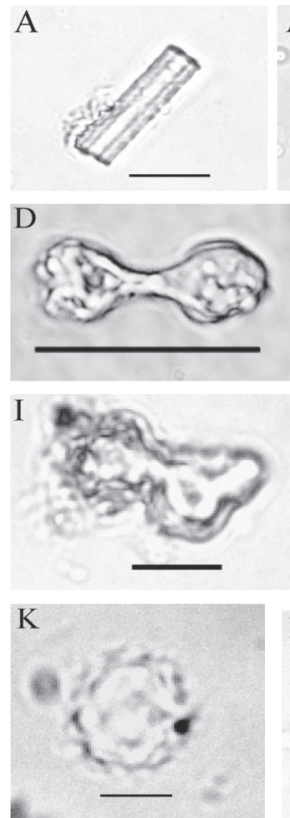

A
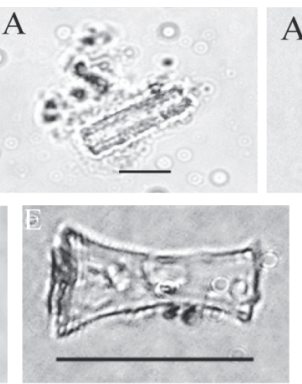

A
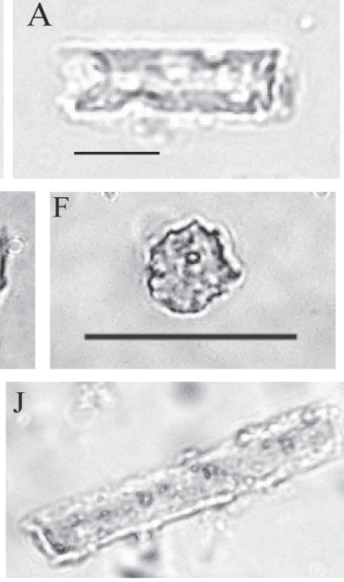

B
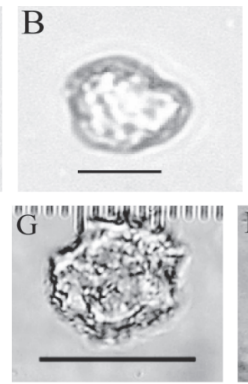

$\mathrm{C}$
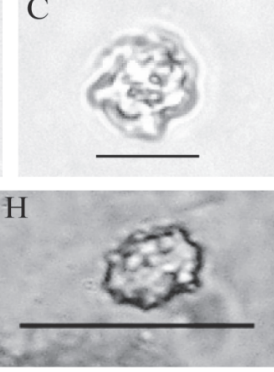

$\mathrm{J}$

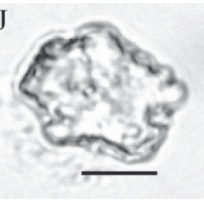

L
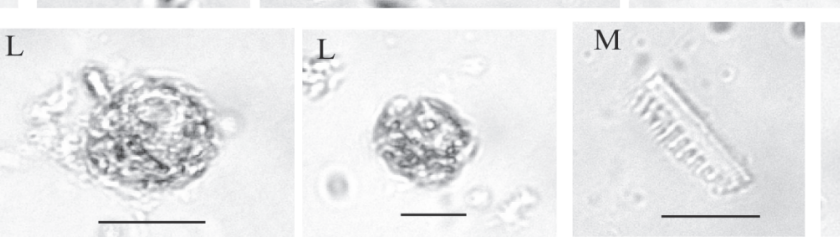

N

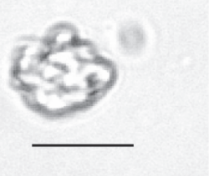

Fig. 2. Exemplos de fitólitos encontrados nos cálculos. Todas as barras de escala possuem $20 \mu \mathrm{m}$, exceto em Enseada 1(30 $\mu \mathrm{m})$. MO-ANT: A. Fitólitos alongados de seção cilíndrica, não identidicados; B. Possivelmente Euphorbiaceae; C. Fitólito esférico de superfície irregular, não identificado. Enseada 1: D. Bilobato comum nas sub-famílias Panicoideae e Bambusoideae; E. Forma comum em Poaceae; F. Possivelmente Araucaria angustifolia (pinhão); G. Forma compatível com Marantaceae; H. Fitólito semelhante aos encontrados em Bromeliaceae. FML-SCR: I. Forma cruciforme freqüente em Panicoidae; J. Fitólitos não identificados. Itacoara: K. Fitólito compativel com Arecaceae; L. Possivelmente Araucaria angustifolia (pinhão); M. Célula longa silicificada, possivelmente Poaceae; N. Não identificado.

\section{Discussão}

A presença de grânulos de amido e suas concentrações médias semelhantes em todas as séries esqueléticas, independentemente da presença de cerâmica nos sítios, indica que vegetais ricos em carboidratos faziam parte da dieta dos grupos de construtores dos sambaquis estudados. Os resultados também indicam que o consumo desse tipo de alimento não se relacionava com a disponibilidade de artefatos cerâmicos, sendo regular nestes grupos considerados pescadores-coletores. Por outro lado, nem a presença ubíqua nem as concentrações encontradas permitem estimar a quantidade de alimento amiláceo efetivamente consumida, já que não há parâmetros estabelecidos para a taxa de preservação de grânulos, nem para a relação entre quantidade consumida e quantidade retida nos cálculos.
A variação dos conjuntos de formas de amido e fitólitos nas diferentes séries parece indicar a seleção diferenciada dos vegetais utilizados, a partir do espectro disponível, segundo padrões de escolha que possivelmente variaram local, temporal e sazonalmente.

O uso de milho (Zea mays), batata-doce (Ipomoea batatas), carás (Dioscorea spp), taioba (Xanthosoma sp) e várias palmeiras (frutos, palmito e amido do tronco) estão documentados na literatura etnográfica brasileira (Galvão 1979; Levi-Strauss 1987; Sauer 1987), assim como a ocorrência de tubérculos, incluindo Dioscorea sp, em sítios de pescadores-coletores em outras áreas do litoral brasileiro (ScheelYbert 2001, 2002). Além disso, restos de frutos de palmeiras estão presentes nos sítios de onde as séries estudadas foram escavadas e incluem jerivá (Syagrus romanzoffiana), descrita na literatura etnográfica como uma das espécies utilizada para 
a obtenção de farinha gomosa a partir do processamento do tronco (Levi-Strauss 1987).

Com base no conhecimento etnográfico, o uso de vegetais pelos grupos estudados já seria esperado. $\mathrm{O}$ estado incipiente do conhecimento atual sobre a apropriação e uso de recursos vegetais por parte de grupos sambaquianos deve-se diretamente às condições precárias de preservação de restos macroscópicos e ao pequeno investimento em estudos de microresíduos nestes sítios. Como decorrência dos achados desta pesquisa passa a ser clara a necessidade imediata do desenvolvimento de modelos de economia e dieta para grupos construtores de sambaquis que sejam menos fortemente apoiados em pesca e coleta de fontes protéicas.

A ocorrência de grânulos de Dioscorea sp exclusivamente nas séries MO-REC e MO ANT, exatamente as que possuem freqüências e prevalências mais elevadas de cárie, sugerem que o aumento de consumo deste tipo de tubérculo seja um dos fatores envolvidos na manifestação da cárie no grupo. Por outro lado, a coincidência de maiores prevalências e freqüências de cáries e de menor variabilidade de formas de grânulos de amido e de fitólitos sugerem um consumo mais intensivo e concentrado em poucas espécies vegetais, o que costuma ser um comportamento indicativo de prática de horticultura, ainda que incipiente. Ao mesmo tempo, a maior variabilidade de formas de grânulos de amido e fitólitos aliada a freqüências e prevalências baixas de cáries nas séries FML-SCR, Enseada I e Itacoara parecem sugerir um quadro com maior ênfase em vegetais coletados e não em vegetais cultivados.

Este consumo diferenciado nas séries MOREC e MO-ANT sugere que uma mudança econômica refletiu-se sobre a dieta, não apenas pela escolha e intensivo consumo de um alimento de origem vegetal específico, mas também pela menor diversidade de fontes de carboidrato incorporadas à dieta.

A presença de areia e de FGE em todas as séries pode estar relacionada aos processos empregados no preparo do alimento, tal como já se assumia a priori com base nos modelos etnográficos e na falta de cerâmica. Os achados dos micro-resíduos de areia e carvão no presente estudo permitem sugerir que formas de preparação que implicassem em assar o alimento em contato com carvão e com o solo (como o uso de fornos escavados) poderiam responder pela presença destes micro-resíduos nos cálculos. Técnicas de cozimento de milho e tubérculos em fornos escavados são referidas repetidamente na etnografia brasileira (Flowers 1983; Galvão 1979).

Areia e cinzas foram freqüentemente identificadas como possíveis agentes causadores dos desgastes dentários severos entre os grupos de pescadores-coletores litorâneos (Mendonça de Souza 1995; Salles-Cunha 1963). Caso a severidade dos desgastes dentários observados nas séries estudadas estivesse diretamente relacionada à ingestão de areia e de fitólitos, uma correlação positiva entre maiores concentrações de areia e de fitólitos e maior freqüência de desgaste severo seria esperada, o que não ocorreu. A análise direta dos dados tampouco sugeriu que esta correlação pudesse estar presente. Por outro lado, a presença destes micro-resíduos nos cálculos indica que eles efetivamente interagiram com as superfícies dentárias e devem ter contribuído para o processo de desgaste dentário destes grupos, provavelmente em conjunto com a ingestão de ossos de peixes e de cinzas como sugerido por Mendonça de Souza (1995).

A relação inversa entre o peso dos cálculos e as concentrações de micro-resíduos observada no presente estudo exige uma explicação, sendo de certa forma inicialmente inesperada. Este resultado pode estar relacionado com variações na velocidade de mineralização da placa, a qual por sua vez é influenciada pela quantidade de proteína que estava sendo ingerida por época da formação de um cálculo específico (Epstein, Mandel e Scopp 1980; Kleinberg et al. 1981; Shasha et al. 1983; Eigner, Jastak, e Bennett 1986; Jin e Yip 2002). Considerando o aumento da precipitação de cálcio em presença de $\mathrm{pH}$ salivar alcalino e a relação proteína/uréia/alcalinidade, é plausível supor que em períodos de maior ingestão de proteína animal a placa fosse mais rapidamente 
mineralizada formando cálculos mais pesados mas menos densos em termos de micro-resíduos retidos em seu interior.

A correlação inversa entre o peso do cálculo e a concentração de micro-resíduos se reproduziu em todas as séries esqueléticas, independentemente das diferenças de tamanho encontradas (Wesolowski 2007), indicando a existência de um processo comum. Uma possibilidade explicativa é a flutuação sazonal na quantidade de proteína consumida pelos grupos, o que seria coerente com os ciclos anuais de maior oferta de pesca observados na região, por exemplo. Este resultado aponta para uma hipótese que deve ser mais bem testada pela arqueologia a partir dos resíduos faunísticos associados a diferentes momentos de construção, ou áreas construídas dos sítios.

Para as séries estudadas, dados relativos à variação sazonal de recursos faunísticos estão disponíveis apenas para o sítio Enseada 1. Bandeira (1992) referiu para esse sítio preponderância do uso de recursos de verão na ocupação mais recente, exatamente aquela à qual a série esquelética analisada está relacionada, e sugeriu abandono parcial do sítio durante os meses de inverno ou o consumo invernal de alimentos armazenados durante o verão. Hipoteticamente, a diminuição de restos faunísticos de espécies típicas de inverno poderia sinalizar uma situação de diminuição de consumo de proteína, mesmo considerando-se estoques de verão, o que poderia influir no processo de formação dos cálculos e na inclusão diferencial de micro-resíduos.

Embora sem condições de comprovação através dos dados até agora disponíveis, é lícito propor, como hipótese, que esses momentos de diminuição de consumo de proteína poderiam ser acompanhados pelo aumento do consumo de vegetais, sobretudo tubérculos, raízes tuberosas e rizomas de vários tipos, além de amidos de goma de tronco de palmeira, recursos que se mantêm disponíveis durante todo o ano. Um quadro de diminuição da ingestão de proteína e aumento da ingestão de alimentos amiláceos teoricamente levaria à mineralização mais lenta de cálculos, que tenderiam a ser mais leves e proporcionalmente mais densos de micro-resíduos.

A presença de fitólitos e grânulos de amido relacionados à sementes de Arancaria angustifolia (pinhão) apenas nos sítios de Forte Marechal Luz, Enseada 1 e Itacoara sugere que os grupos que habitaram estes sítios mantiveram contato com o planalto, reforçando um modelo arqueológico vigente (Chmyz 1976; Schmitz 1988; Schmitz et al. 1993) No caso de Itacoara, a localização mais interior e a ocorrência de artefatos confeccionados em matérias-primas originárias da área do planalto reforçam a existência dessa ligação. No caso de Enseada 1, a possibilidade de abandono parcial do sítio no inverno, indicada pelos dados da zooarqueologia, condiz com o momento de disponibilidade de pinhões, sugerindo que parte do grupo poderia incursionar ao planalto a fim de coletar esse recurso. Quanto ao Forte Marechal Luz características de morfologia craniana distinta já sugeriam a possibilidade de contatos com outras regiões. A distância entre sítios de Forte Marechal Luz e Enseada 1 e a vertente da serra pode ser transposta, por exemplo, pela calha do Rio Cubatão, um canal natural através do qual o acesso à serra situa-se a menos de $20 \mathrm{~km}$ de distância. No caso dos três sítios a presença de cerâmica Itararé também aponta para contatos com o planalto.

Ambas as séries, Itacoara e Enseada 1, apresentam datações sobrepostas ao momento de maior expansão da Mata de Pinhais, a qual se expandiu pela encosta da serra e pelas calhas dos rios ao redor de 1000 anos BP (Behling 1998, 2001). Analisando conjuntamente as coincidências de datações, a presença de grânulos de amido e fitólitos de pinhão exclusivamente nestas séries e os dados arqueológicos indicativos do contato com o planalto, é possível sugerir que ambos os grupos aproveitaram-se de um recurso dietético fortemente previsivel (pois que sempre disponível no inverno) e abundante, que se tornara disponível naquele momento temporal.

A recuperação e análise dos micro-vestígios vegetais retidos nos cálculos dentários dos grupos estudados possibilitou a produção de novos dados sobre sua subsistência, ampliando o conhecimento sobre o espectro vegetal por eles 
utilizado. Tornou possivel também a produção de um conjunto independente de evidências, o qual reforça a hipótese arqueológica do contato entre grupos litorâneos e o planalto no período mais recente de ocupação do litoral norte de Santa Catarina. A expansão do mesmo tipo de abordagem investigativa para outras séries esqueléticas de pescadores-coletores tem potencial para produzir uma massa de dados inteiramente novos, os quais podem contribuir consistentemente para melhorar a compreensão da subsistência e do modo de vida destes grupos.

\section{Agradecimentos}

À CAPES pelo apoio financeiro. Aos laboratórios de Anatomia Vegetal e Fisiologia Vegetal do Departamento de Botânica, Instituto de Biociências, Universidade de São Paulo, por autorizarem o uso de espaços e equipamentos. Ao Setor de Antropologia Biológica, Departamento de Antropologia do Museu Nacional, UFRJ e ao Museu Arqueológico de Sambaqui de Joinville por autorizarem o acesso aos acervos e aos laboratórios. A Giuliano Locosselli pela análise estatística.

WESOLOWSKI, V.; MENDONÇA DE SOUZA, S.M.F.; KARL REINHARD, K.; CECCANTINI, G. Starch grains and Phytoliths in human dental calculus: contribution to the study of life style and subsistence at Sambaqui groups in Brazilian southern coast. Revista do Museu de Arqueologia e Etnologia, São Paulo, 17: 191-210, 2007.

Abstract: The aim of this paper is to present the analysis of micro-residues recovered from fishers-gatherers dental calculus. All analyzed groups are from southern Brazilian shell-mounds. The relationships found between microresidues and dental physiopathology is presented too.

The dietary consumption of starchy vegetables was evidenced in all studied groups, independently of the presence of ceramic in the sites. The results point to different choice patterns concerning edible vegetables. The contact between seashore and inland are evidenced too.

Keywords: Shell-mounds - Fisher-gatherers - Starch - Phytoliths - Caries - Tooth wear.

\section{Referências bibliográficas}

AFONSO, M.C.

1999 O sambaqui Espinheiros II: uma contribuição à arqueologia do litoral norte de Santa Catarina. Revista do CEPA, 23: 119-123.

AFONSO, M.C.; DE BLASIS, P.

1994 Aspectos da formação de um grande sambaqui: alguns indicadores em Espinheiros II, Joinville. Revista do Museu de Arqueologia e Etnologia, 4: 21-30.
ARMITAGE, P.L.

1975 The extraction and identification of opal phytoliths from the teeth of ungulates. Journal of Archaeological Science, 2: 187-197.

\section{BANDEIRA, D.R.}

1992 Mudança na estratégia de subsistência do sítio arqueológico Enseada I - Um estudo de caso. Dissertação de Mestrado. Universidade Federal de Santa Catarina, Florianópolis. 
2004 Ceramistas pré-coloniais da baía da Babitonga, SC : Arqueologia e etnicidade. Tese de doutorado. Universidade Estadual de Campinas, Campinas.

BARTON, H.; MATTHEWS, P.J.

2006 Taphonomy. R. Torrence; H. Barton (Orgs.) Ancient starch research. Walnut Creek, Left Coast press: 75-94.

BECK, A.

1974 O Sambaqui de Enseada I - SC LN 71. um estudo sobre tecnologia pré-histórica. Tese de Livre Docência. Universidade Federal de Santa Catarina, Florianópolis.

1972 A variação do conteúdo cultural dos sambaquis do Litoral de Santa Catarina. Tese de Doutorado. FFLCH, Universidade de São Paulo, São Paulo.

1971 Grupos cerâmicos do litoral de Santa Catarina - Fase Rio Lessa e Fase Enseada. Anais do Museu de Antropologia da UFSC, 4: 25-9.

BECK, A.; DUARTE, G.M.; REIS, M.J.

1969 Sambaqui do Morro do Ouro. Nota prévia. Pesquisas, 20: 31-40.

BECK, A.; ARAÚJO, E.M; DUARTE, G.M.

1970 Síntese da arqueologia do litoral norte de Santa Catarina. Anais do Museu de Antropologia da UFSC, 3: 23-48.

BEHLING, $\mathrm{H}$.

1998 Late quaternary vegetational and climatic changes in Brazil. Reviews of Palaeobotany and Palynology, 99: 143-156.

2001 Tropical rain Forest and climate dynamics of the Atlantic lowland southern Brazil, during the late quaternary. Quarternary Research, 56: 383-89.

BRYAN, A.L.

1993 The Sambaqui at Forte Marechal Luz, State of Santa Catarina, Brazil. Corvallis: Center for the Study of the First Americans/ Oregon State University.

CHMYZ, I.

1976 A ocupação do litoral dos estados do Paraná e Santa Catarina por povos ceramistas. Estudos Brasileiros, 1: 7-43.

COHEN, M.N.; ARMELAGOS, G,J.

1984 Paleopathology at the origins of agriculture. Nova York: Academic Press.

DANIELSON, D.R.; REINHARD, K.J.

1998 Human dental microwear caused by calcium oxalate phytoliths in prehistoric diet of Lower Pecos Region, Texas. American Journal of Physical Anthropoloy, 107: 297-304.
EIGNER, T.L.; JASTAK, J.T.; BENETT, W.M.

1986 Achieving oral health in patients with renal failure and renal transplants. Journal of American Dentistry Association, 113: 612-16.

EPSTEIN, S.R.; MANDEL, I.D.; SCOPP, I.W.

1980 Salivary composition and calculus formation in patients undergoing hemodialysis. Journal of Periodontoloy, 51: 336-8.

FIGUTI, L.

1993 O homem pré-histórico, o molusco e o sambaqui: considerações sobre a subsistência dos povos sambaquieiros. Revista do Museu de Arqueologia e Etnologia, 3: 67-80.

1992 Les sambaquis COSIPA (4200 à 1200 ans BP): étude de la subsistance chez les peuples préhistoriques de pêcheursramasseurs de bivalves de la côte centrale de l'etat de São Paulo, Brésil. Tese de doutorado. Museum National d'Histoire Naturelle, Paris.

FLOWERS, N.M.

1983 Seasonal factors in subsistence, nutrition and child growth in a central Brazilian Indian community. In: Hames, R.B.; Vickers, W.T. (Eds.) Adaptive responses of native Amazonians. Nova York: Academic Press.

FOX, C.L.; JUAN, J.; ALBERT, R.M.

1996 Phytoliths analysis on dental calculus, enamel surface, and burial soil: Information about diet and paleoenvironment. American Journal of Physical Anthropology, 101: 101-113.

FOX, C.L.; PÉREZ-PÉREZ, A.

1994 Dietary information through the examination of plant phytoliths on the enamel surface of human dentition. Journal of Archaeological Science, 21: 29-34.

GALVÃO, E.

1979 Encontro de sociedades: Indios e Brancos no Brasil. Rio de Janeiro: Paz e Terra.

GARCIA, C.R.

1972 Estudo comparativo das fontes de alimentação de duas populações préhistóricas do litoral paulista. Tese de Doutorado. Instituto de Biociências, Universidade de São Paulo, São Paulo.

GASPAR, M.D.

1998 Considerations of the sambaquis of the Brazilian coast. Antiquity, 72: 592-615.

2000 Sambaqui: Arqueologia do litoral brasileiro. Rio de Janeiro: Jorge Zahar Editor. 
GOODMAN, A.H.; LALLO, J.; ARMELAGOS, G.J; ROSE, J.C.

1984a Health changes at Dickinson Mounds, Illinois (AD 950-1300). In: Cohen, M.N.; Armelagos, G.J. (Eds.) Paleopathology at the origins of agriculture. Nova York, Academic Press: 271-306.

GOODMAN, A.H.; MARTIN, D.L.; ARMELAGOS, G.J.; CLARK, G.

1984b Indications of stress from bone and teeth. In: Cohen, M.N.; Armelagos, G.J. (Eds.) Paleopathology at the origins of agriculture. Nova York, Academic Press: 13-49.

GOULART, M.

1980 Tecnologia e padrões de subsistência de grupos pescadores-coletores préhistóricos, habitantes do sambaqui do Morro do Ouro - Joinville, Santa Catarina. Relatório de pesquisa. Museu Arqueológico de Sambaqui de Joinville, Joinville.

HANSEL, F.A.; SCHMITZ, P.I.

2006 Classificação e interpretação dos resíduos orgânicos preservados em fragmentos de cerâmica arqueológica por cromatografia gasosa e cromatografia gasosa-espectrometria de massas. Pesquisas, 63: 81-112.

HÜBBE, M.O.R.

2005 Análise Biocultural dos remanescentes ósseos humanos do sambaqui porto do Rio Vermelho 02 (SC-PRV-02). Tese de doutorado. Instituto de Biociências, Universidade de São Paulo, São Paulo.

JIN, Y.; YIP, H.K.

2002 Supragengival calculus: Formation and control. Critical Review of Oral Biology and Medicine, 13: 426-441.

KLEINBERG, I.; JENKIS, G.N.; DENEPITIYA, L.; CJATTERJEE, R.

1981 Diet and dental plaque. In: Fergunson, D.B. (Ed.) The environment of the teeth. Nova York, Kargel: 88-107.

LARSEN, C.S.

1981 Skeletal and dental adaptations to the shift to agriculture on the Georgia Coast. Current Anthropology, 22: 422-23.

1984 Health and disease in prehistoric Georgia: the transition to agriculture. In: Cohen, M.N.; Armelagos, G.J. (Eds.) Paleopathology at the origins of agriculture. Nova York, Academic Press: 367-92.

LARSEN, C.S.; SCHOENINGER, M.J.; SHAVIT, R.; RUSSELL, K.F.

1990 Dietary Transition on the Southeastern
U.S. Atlantic coast. International Journal of Anthropology, 5: 333-46.

LEVI-STRAUSS, C.

1987 O uso das plantas silvestres da América do Sul tropical. Ribeiro, B.G. (Coord.) . Suma Etnológica Brasileira, vol 1, Etnobiologia. Petrópolis, Editora Vozes: 29-46.

LIMA, T.A.

1991 Dos mariscos aos peixes: um estudo zooarqueológico de mudança de subsistência na pré-história do Rio de Janeiro. Tese de Doutoramento. FFLCH, Universidade de São Paulo, São Paulo.

LOY, T.H.

1994 Methods in the analysis of starch residues on prehistoric stone tools. In: Hather, J.G. (Ed.) Tropical archaeobotany: Applications and new developments. Londres, Routledge: 86-114.

LOY, T.H.; SPRIGGS, M; WICKLER, S.

1992 Direct evidence for human use of plants 28,000 years ago: starch residues on stone artifacts from the northern Solomon Islands. Antiquity, 66: 898-912.

MELLO E ALVIM, M.C.

1978 Caracterização da morfologia craniana das populações pré-históricas do litoral meridional brasileiro (PR e SC). Arquivos de Anatomia e Tecnologia, 3: 292-318.

MELLO E ALVIM, M.C.; MELLO FILHO, D.P.

1967/68 Morfologia da população do Sambaqui do Forte Marechal Luz (Santa Catarina). Revista de Antropologia, 15/16: 5-14.

MENDONÇA DE SOUZA, S.M.F.

1995 Estresse, doença e adaptabilidade: Estudo comparativo de dois grupos préhistóricos em perspectiva biocultural. Tese de Doutorado. Escola Nacional de Saúde Pública, Fiocruz, Rio de Janeiro.

1999 Osteologia humana, paleopatologia e inferência arqueológica: Uma reflexão sobre o valor dos dados. In: Mazz, J.M.L.; Sans, M. (Eds.) Arqueologia y Bioantropologia de las tierras bajas. Montevideo, Faculdad de humanidades y ciencias de la education/ Universidad de la República: 189-203.

MIDDLETON, W.

1990 An improved method for extraction of opal phytolith from cervid dental tartar. The Phytolitarien Newsletter, 6: 2-5.

NEVES, W.A.

1988 Paleogenética dos grupos pré-históricos do litoral sul do Brasil (Paraná e Santa Catarina). Pesquisas, 43. 
NEVES, W.A; BLUM, M.

1998 Afinidades Biológicas entre populações pré-históricas do centro-sul brasileiro: uma análise multivariada. Fronteiras Revista de História da UFMS, 2: 143-69.

NEVES, W.A.; WESOLOWSKI, V.

2002 Economy, nutrition and disease in prehistoric coastal Brazil: A case study from the state of Santa Catarina. In: Steckel, R.H.; Rose, J.C. (Eds.) The backbone of History: Health and nutrition in the western hemisphere. Cambridge, Cambridge University Press: 376-405.

OLIVEIRA, M.S.C.

2000 Os sambaquis da planície costeira de Joinville, litoral norte de Santa Catarina: Geologia, paleogeografia e conservação in situ. Dissertação de mestrado. Centro de Filosofia e Ciências Humanas, Universidade Federal de Santa Catarina, Florianópolis.

PEARSALL, D.M.

2000 Paleoethnobotany: A handbook of procedures. Nova York: Academic Press.

PETRYKOWSKI, S.P.

2006 Estudo da anatomia vegetal e paleobotânica dos trançados de fibras vegetais encontrados no sambaqui Cubatão I, Joinville, SC. Monografia de conclusão de graduação. Universidade da Região de Joinville, São Francisco do Sul.

PIAZZA, W.

1974 Dados à arqueologia do litoral norte e do planalto de Canoinhas. PRONAPA, Resultados do 5oano, 1969-1970. Publicações Avulsas do Museu Paraense Emílio Goeldi, 26: 53-66.

PIPERNO, D.R.

1985 Phytholith taphonomy and distribution in archaeological sediments from Panamá. Journal of Archaeological Science, 12: 247-269.

PIPERNO, D.R.; HOLST, I.

1998 The presence of starch grains on prehistoric stone tools from the humid neotropics: indications of early tuber use and agriculture in Panama. Journal of Archaeological Science, 25: 765-776.

PIPERNO, D.R.; RANERE, A.J.; HOLST, I.; HANSELL, P.

2000 Starch grains reveal early root crop horticulture in the Panamanian tropical forest. Nature, 407: 894-7.

PROUS, A.

1977 Principaux sites prehistoriques de l'etat de Santa Catarina. In : Prous, A.; Piazza, W.F. (Eds.) Documents pour la Préhistoire du Brésil Méridional 2. L'état de Santa Catarina. Cahier d'archéologie d'Amérique du Sud, 5: 65-114.

1991 Arqueologia Brasileira. Brasília: Editora Universidade de Brasília.

2006 O Brasil antes dos brasileiros: A pré-história do nosso país. Rio de Janeiro: Jorge Zahar Editor.

REINHARD, K.J.; MENDONÇA DE SOUZA, S.F.; RODRIGUES, C.; KIMERLE, E.; DORSEY. VINTON, S.

2001 Microfossils in dental calculus: A new perspective on diet and dental disease. In: Williams, E. (Ed.) Human remain: Conservation, retrieval and analysis. Proceedings of a conference held in Willianburg, VA, nov 1999. BAR International Series 934: 113-118.

ROHR, J.A.

1961 Pesquisas paleo-etnográficas na Ilha de Santa Catarina e notícias prévias sobre sambaquis da Ilha de São Francisco do Sul III. Pesquisas, 12.

ROSE, J.C.; BURNETT, B.A.; NASSANEY, M.S.; BLAEUER, N.W.

1984 Paleopathology and the origins of maize agriculture in Lower Mississippi Valley and Caddoan culture areas. In: Cohen, M.N.; Armelagos, G.J. (Eds.) Paleopathology at the origins of agriculture. Nova York, Academic Press: 393-424.

SALLES-CUNHA, E.

1963 Sambaquis e outras jazidas arqueológicas: paleopatologia dentária e outros assuntos. Rio de Janeiro: Editora Científica.

SAUER, C.O.

1987 As plantas cultivadas na América do Sul tropical. Ribeiro, B.G. (Coord.) Suma Etnológica Brasileira, vol 1, Etnobiologia. Petrópolis, Editora Vozes: 59-90.

SCHEEL-YBERT, R.

2001 Man and vegetation in southeastern Brazil during the late holocene. Journal of Archaeological Science, 28: 471-80.

2002a Late Holocene south-eastern Brazilian fisher-gather-hunter: environment, wood exploitation and diet. In: Thiébault, S. (Ed.) Charcoal analysis: Methodological approaches, palaeoecological results and wood uses. Proceedings of the seconde international meeting of anthracology. Paris, Archaeopress: 159-168. 
2002b Mise en évidence par l'analyse anthracologique de la stabilité de la végétation sur le litoral brésilien pendant l'holocène supérieur. Quaternaire, 13: $247-256$

SCHMITZ, P.I.

1988 As tradições ceramistas do planalto sulbrasileiro. Documentos, 2: 75-130.

SCHMITZ, P.I.; VERARDI, I.; DE MASI, M.N.; ROGGE, J.H.; JACOBUS, A.L.

1993 Escavações arqueológicas do Pe. João Alfredo Rohhr, S.J. O sítio da praia das Laranjeiras II: uma aldeia da tradição ceramista Itararé. Pesquisas, 49.

SHASHA, S.M.; BEN ARYEH, H.; ANGEL, A.; GUTMAN, D.

1983 Salivary content in hemodialysed patients. Journal of Oral Medicine, 38: 67-70.

TIBURTIUS, G.

1996 Arquivos de Guilherme Tiburtius I. Joinville, Museu Arqueológico de Sambaqui de Joinville/ Fundação Cultural de Joinville.

TIBURTIUS, G.; BIGARELLA, J.J.; BIGARELLA, I.K.

1951 Nota prévia sobre a jazida paleoetnográfica de Itacoara, Joinville, Santa Catarina. Ciência e Cultura, 3: 267-8.

TORRENCE, R.; BARTON, H.

2006 Ancient starch research. Walnut Creek: Left Coast press.

TURNER II, C.G.

1979 Dental anthropological indications of agriculture among the Jomon people of central Japan. American Journal of Physical Anthropology, 51: 619-36.

UGENT, D.; POZORSKY, S.; POZORSKY, T.

1986 Archaeological manioc (Manioh) from costal Peru. Economic Botany, 40: 78-102.
VAN PEER, P.; FULLAGAR, R.; STOKES, S.; BAILEY, R.M.; MOEYERSONS, J.; STEENHOUND, F.

2003 The Early to Middle Stone Age transition and the emergence of modern human behavior at site $8-$ B - 11, Sai island, Sudan. Journal of Human Evolution, 45: 187-93.

WALSHAW, S.C.

1999 Reconstruction of environment in early Bronze Age Syria through phytolith analysis from dental calculus. Dissertação de Mestrado. Departamento de Antropologia, Universidade de Alberta, Alberta.

WARNOCK, P.; REINHARD, K.J.

1992 Methods of extracting pollen and parasites egges from latrine soils. Journal of Archaeological Science, 19: 261-64.

WESOLOWSKI, V.

2000 A prática da horticultura entre os construtores de sambaquis e acampamentos litorâneos da região da Baía de São Francisco, Santa Catarina: Uma abordagem bio-antropológica. Dissertação de mestrado. FFLCH, Universidade de São Paulo, São Paulo.

2007 Cáries, desgaste, cálculos dentários e micro-resíduos da dieta entre grupos pré-históricos do litoral norte de Santa Catarina: É possível comer amido e não ter cárie? Tese de doutorado. Escola Nacional de Saúde Pública Sérgio Arouca, Fiocruz, Rio de Janeiro.

WIERNER, C.

1876 Estudos sobre os sambaquis do sul do Brazil. Boletim do Museu Nacional, 1: 1-20. 